\title{
El Ateneo Mexicano (1840-1850): una constelación cultural intergeneracional
}

\author{
The Ateneo Mexicano (1840-1850): an \\ intergenerational cultural constellation
}

\author{
ERIKA Madrigal HernándeZ ${ }^{1}$ \\ ORCID: https://orcid.org/0000-0002-0816-9455 \\ Universidad Nacional Autónoma de México \\ erika.madrigal1@hotmail.com
}

Resumen:

El objetivo de esta investigación es analizar a la asociación literaria del Ateneo Mexicano (1840-1850), que reunió a la clase intelectual y política de la época que dominó el espacio público. En este artículo analizo el origen de esta asociación literaria, los objetivos que llevaron a reunir a un grupo intergeneracional, multidisciplinario y heterogéneo ideológicamente, así como sus aportaciones en el campo intelectual y de la cultura escrita. En mi análisis propongo al Ateneo Mexicano como una constelación

${ }^{1}$ UNAM, Programa de Becas Posdoctorales en la UNAM, becaria del Instituto de Investigaciones Bibliográficas, asesor doctor Alejandro González. Esta publicación retoma elementos centrales de mi tesis doctoral inédita presentada en la University of St Andrews dirigida por el Dr. Will Fowler, sobre la cual profundizo en mi investigación actual. 
cultural que reunió a dos generaciones, las cuales identifico como los consagrados y los jóvenes. En este marco, sugiero que, en la medida en que el Ateneo Mexicano conjugó a un grupo intergeneracional y multidisciplinario con los personajes más doctos en sus materias, el grupo propició un auge cultural en la organización, producción y difusión del conocimiento, que condujo también hacia un nuevo orden en la opinión pública a través de la instrucción de los "nuevos" ciudadanos del México independiente.

Palabras clave:

cultura escrita en el siglo XIX, asociaciones científico-literarias, educación cívica, construcción de ciudadanía, intelectuales mexicanos.

Abstract:

The aim of this research is to examine the literary association El Ateneo Mexicano (1840-1850), which congregated the intellectual and political class that dominated the public space in Mexico. The purpose is to analyse its origins and the goals that brought an intergenerational, multidisciplinary, and ideologically heterogeneous group together, as well as its contribution in the intellectual and written culture fields. In this study, I propose the Ateneo Mexicano as cultural constellation gathering two generations, which I identify as the consecrated and the young. Likewise, it is suggested that the conjunction of an intergenerational and multidisciplinary group, with the most learned personalities in their subjects, fostered a cultural upsurge in the organization, production, and dissemination of knowledge, which also led to a new order in public opinion through the instruction of "new" citizens of the Independent Mexico. 
Key words:

written culture in the $19^{\text {th }}$ century, scientific-literary associations, civic education, building citizenship, Mexican intellectuals.

Recibido: 02 de junio de 2021 Aceptado: 23 de noviembre de 2021

DOI: https://doi.org/10.36798/critlit.v0i24.401

"El Ateneo, asociación literaria a la que perteneció lo más distinguido de los hombres instruidos de México, está hoy olvidado" (Lafragua y Orozco 324). Tan solo una década después de haber sido fundado el Ateneo Mexicano, uno de sus miembros más eminentes, José María Lafragua expresaba con una clara y razonable nostalgia el olvido en el que había caído esta asociación. Esta nostalgia se debe a que el Ateneo Mexicano, para 1844, había sido reconocido como "la sociedad más ilustrada de la República", por ser esta asociación la que congregaba a "los hombres más celebres" de México ("Carta de Ramón Luna” 517).

Con base en la anterior reflexión, el objetivo de esta investigación es rescatar del olvido a la asociación literaria del Ateneo Mexicano que, en tanto que reunió a la clase intelectual y política que dominó en la opinión pública durante el primer medio siglo de vida independiente, amerita un estudio mayor del que hasta el momento ha recibido, para así conocer el perfil de sus miembros, sus propósitos intelectuales comunes y sus estrategias de vinculación. Con ello mi intención es contribuir a clarificar el periodo correspondiente de la historia de la cultura escrita e intelectual de México.

La historiografía ha ubicado a dos cenáculos intelectuales cumbres en el impulso del desarrollo intelectual en México durante el siglo XIX. El primero de ellos es la Academia de Letrán (1836), considerada como el crisol intelectual de la primera mitad de siglo; el se- 
gundo es el grupo que se conformó en torno a la revista Renacimiento (1869), estimado como el grupo que logró la consolidación de una literatura denominada nacional. ${ }^{2}$ Con relación a esta última, tanto Pablo Mora como Nicole Giron han identificado la aportación de Ignacio Manuel Altamirano, como la culminación de este proceso, refiriéndolo, respectivamente, como "el apostolado" o "el campeón" de la literatura nacional. ${ }^{3}$ Si bien identifico al Ateneo Mexicano en

${ }^{2}$ Alicia Perales Ojeda y Marco Antonio Campos destacan el papel relevante de la Academia de Letrán como una asociación que figura como un punto de inicio en la creación de una "literatura mexicana". Por su parte, Gerardo Bobadilla destaca el desempeño de la Academia de Letrán como una asociación que fomentó la circulación de la estética romántica a través de textos de autores como Lord Byron, Víctor Hugo y Alejandro Dumas, por mencionar algunos, agilizando el "acceso casi inmediato o con escasa diferencia de tiempo" a sus publicaciones originales (78). Para estudios que también mencionan la relevancia de la Academia de Letrán y de la revista Renacimiento en la tradición literaria en México, ver: Martínez, José Luis. La expresión nacional, letras mexicanas del siglo XIX. UNAM, 1955; Saborit, Antonio, et al., coordinadores. La literatura en los siglos XIX y XX. CONACULTA, 2013; Clark de Lara, Belem y Elisa Speckman Guerra, editoras. La República de las letras asomos a la cultura escrita del México decimonónico. Ambientes, asociaciones y grupos. Movimientos, temas y géneros literarios. Vol. 1, UNAM, 2005; Martínez Luna, Esther. Dimensiones de la cultura literaria en México (1800-1850). Modelos de sociabilidad materialidades, géneros y tradiciones intelectuales. UNAM, 2018; Ruedas de la Serna, Jorge. La formación de la literatura nacional (1805-1850) Prolegómenos y Los cimientos del sistema. T. I y II, UNAM, 2010.

${ }^{3}$ Asimismo, como parte de esta trayectoria se han destacado otros dos grupos: la Arcadia de México, como un gremio de intelectuales preindependistas, precursor en la conformación del nacionalismo literario en México y, en el periodo de posguerra, el Liceo Hidalgo (1849). Ver respectivamente: Ruedas de la Serna, Jorge. "De zagales y mayorales. Notas para la historia de la Arcadia de México". La República de las letras asomos a la cultura escrita del México decimonónico. Vol. I. Ambientes, asociaciones y grupos. Movimientos, temas y géneros literarios. Editado por Belem Clark de Lara y Elisa Speckman Guerra, UNAM, 2005; Clark de Lara, Belem. Hacia una historia del Liceo Hidalgo y la construcción de la literatura mexicana. UNAM, 2017. 
el inter de estos dos momentos como un grupo que continuó dicha narrativa discursiva de exaltación nacional, por mi parte, mi análisis se enfoca en sugerir al Ateneo Mexicano como un grupo bisagra que interconectó a estas dos coordenadas cúspides, es decir, la Academia de Letrán y el Renacimiento. Así, el propósito de este estudio es dilucidar la aportación del Ateneo Mexicano, que provisto de intereses pedagógicos, periodísticos, editoriales y científicos, dotó de originalidad su empresa intelectual en la trayectoria de la tradición de la cultura escrita y de la historia intelectual en México.

Con base en lo que hasta aquí he señalado, los objetivos de mi análisis son: 1) explicar el proceso de fundación del Ateneo Mexicano, 2) conocer los objetivos que llevaron a reunir a un grupo heterogéneo -generacional, disciplinario e ideológicamente- , 3) proponer la conformación y operación del grupo referido, en el campo intelectual y de la cultura escrita, como una constelación cultural.

En el presente estudio, propongo al Ateneo Mexicano como una constelación cultural intergeneracional, la cual reunió a dos generaciones que aquí identifico como los ateneístas consagrados y los jóvenes, que corresponden a la primera generación del México independiente y a la generación de la Reforma, respectivamente. En este sentido, sugiero que la conjunción de este grupo intergeneracional, multidisciplinario y heterogéneo ideológicamente, posibilitó la congregación de los personajes más doctos en sus materias. De este modo, la originalidad de la asociación del Ateneo Mexicano quedó resuelta en una empresa intelectual de carácter predominantemente pedagógico con una dimensión sociocultural, la cual condujo al grupo a romper con el modelo de tertulia cerrada o delimitada exclusivamente a una élite que predominaba en ese momento, promoviendo una intervención social a través de la instrucción. 


\section{EL ATENEO MEXICANO: CONSTELACIÓN CULTURAL}

En la trayectoria entre la Academia de Letrán y el Renacimiento emergió un importante número de asociaciones y de revistas literarias, tales como: El año nuevo (1837-1840), el Registro Trimestre (1832-1833), El Amigo de la Juventud (1835), la Revista Mexicana (1835), el Mosaico Mexicano (1836-1842), el Liceo Mexicano (1844), el Museo Mexicano (1843-1845), entre otras. Todas estas compartieron con el Ateneo Mexicano objetivos como el forjar una nación a través de las letras, así como el congregar a importantes personajes del campo de la política y de la cultura. Sin embargo, no pocos especialistas coinciden en el hecho de que la publicación El Ateneo Mexicano. Omnium Utilitati destacó sobre sus contemporáneas. Al respecto, María del Carmen Ruiz Castañeda considera que El Ateneo Mexicano fue "protagonista", debido a que su labor representó "la culminación de la tendencia [de posicionamiento] cultural sostenida por el periodismo mexicano durante las primeras décadas" (45). Otro aspecto que ha destacado Laura Suárez de la Torre es que el grupo "se atrevió a presentar una novedad" en su contenido, debido a que no solo se abasteció de textos extranjeros, sino que reveló "la configuración de un grupo cultural de orientación académica” (153). Por su parte, Beatriz Urías ha destacado el relevante papel del grupo en el proceso de la democratización de la educación. ${ }^{4}$ Justamente, estas reiteraciones sobre rasgos

${ }^{4}$ Acerca de estudios dirigidos al análisis del Ateneo Mexicano, ver: Ruiz Castañeda, María del Carmen. "El Ateneo Mexicano. Omnium Utilitati. Órgano de la Asociación del mismo nombre (1844-1845)". Ciencias y desarrollo, 24, no. 138, enero-febrero 1998, pp. 65-71; Urías, Beatriz. "Educación para la democracia". Estudios, no. 12, 1988, pp. 29-51. María del Carmen Ruiz Castañeda enfoca su análisis a la organización y contenido general de la revista que publicó el grupo. Beatriz Urías, por su parte, estudia la propuesta del grupo como un aporte a la democratización de la instrucción pública. Para un análisis del Ateneo Mexicano en el campo de la Geografía, ver: Sabas Silvia, Ana Lilia. "Una aproximación al 
relevantes del grupo, me han motivado a indagar sobre su origen, los objetivos de su proyecto literario y sus alcances. En este tenor, otro aspecto que me permite ubicar al Ateneo Mexicano como una asociación neurálgica de su época es su carácter apolítico, lo cual le permitió congregar un foro ideológicamente heterogéneo, pues reunió a los intelectuales más destacados sin distinción de partido. De este modo, destacó frente a otras revistas contemporáneas que operaron como publicaciones antagónicas tales como el Liceo Mexicano (1844) y el Museo Mexicano (1843-1844, 1845) (Perales 79).

El Ateneo Mexicano fue una asociación literaria organizada en 1840. A lo largo de su existencia como entidad grupal contó entre 40 y 65 miembros, ${ }^{5}$ y publicó su propia revista titulada El Ateneo Mexicano. Omnium Utilitati (1844-1845). ${ }^{6}$ La asociación congregó tanto a la intelectualidad mexicana, como a los primeros hombres de Estado que construyeron las instituciones en el México recién independiente. Resulta clave destacar este último aspecto, debido a que, como veremos en lo sucesivo, justamente el perfil público de la gran mayoría de los ateneístas, les permitió identificar problemas sociales

asociacionismo científico de la primera mitad del siglo XIX. El caso de la Historia Natural y la Geografía en el Ateneo Mexicano". Geografia e Historia Natural: hacia una historia comparada. Estudio a través de Argentina, México, Costa Rica y Paraguay (Geonaturalia), coordinado por Cecilia A. Lértora Mendoza, Ediciones FEPAI, 2008, pp. 91-129. Para el planteamiento del análisis del Ateneo Mexicano como una constelación ver: Madrigal Hernández, Erika. The Ateneo Mexicano: the cultural constellation of mid-nineteenth century Mexico, 1840-1850. 2019. University of St. Andrews, Tesis doctoral.

${ }^{5}$ En la lista de miembros inscritos al Ateneo Mexicano, publicada en 1840, se muestra un total de 65 individuos ("Lista de los individuos" 262).

${ }^{6}$ Para diferenciar a la revista de la asociación, a lo largo de este trabajo se referirá a la primera por su título: El Ateneo Mexicano. Omnium Utilitati y, a la segunda, como "el Ateneo Mexicano". De la revista se conocen los tomos I y II en los que se compila lo publicado en 1844 y 1845, respectivamente. 
concretos y formular un programa de instrucción multidisciplinario no especializado que permitiera formar a diversos sectores sociales. ${ }^{7}$

Como parte de mi planteamiento, propongo al grupo como una constelación y no como una generación, debido a que en el Ateneo confluyeron dos generaciones que, como se mencionó, he denominado los jóvenes y los consagrados. En este sentido, planteo la constelación como una unidad con caracteres diversos que conforman una estructura, la cual forma parte de un entramado de mayor extensión, que figura como un "microcosmos" dentro de un "macrocosmos" (Benjamin 208). ${ }^{8}$ Estas imágenes de igual manera permiten ubicar el sentido sincrónico y diacrónico de mi análisis. De este modo, la constelación del Ateneo agrupó a personajes de diferentes generaciones, disciplinas e ideologías, los cuales se congregaron a partir de una fuerte tendencia en común: impulsar un nuevo orden social a partir de "la instrucción de las masas” (Reglamento 27). Este interés común permitió a los ateneístas vincularse, en un momento específico, independientemente de sus distintas edades, afiliaciones políticas y campos de conocimiento. Asimismo, la luz constelar del Ateneo trascendió a la segunda mitad de siglo a través de los ateneístas jóvenes. Belem Clark de Lara en su planteamiento de "¿Generaciones o Constelaciones?" señala que la categoría de constelación, aplicada al estudio de la historia literaria de acuerdo con lo propuesto por Fernando Curiel:

significa la posibilidad de reconocer formas culturales producto de la participación de intelectuales de distintas edades a los que

${ }^{7}$ En el estudio que he realizado sobre la Cartilla de bistoria (1829), la Cartilla social (1836) y la Cartilla moral militar (1839) publicadas por José Gómez de la Cortina, he observado que la labor pública de los ateneístas influyó en su creación intelectual, la cual dirigieron a resolver temas de impacto social.

${ }^{8}$ Benjamin señala que el "microcosmos" y el "macrocosmos" son "una de las muchísimas versiones que la experiencia de la semejanza ha ido encontrando a lo largo de la historia" (208). 
unen, en ese específico momento estelar, propósitos semejantes. Algunas constelaciones siguen rutilando mucho tiempo después de su extinción. Por lo tanto sirven para orientarnos en el espeso bosque cultural. (16) ${ }^{9}$

Aunque la noción de constelación remite a otras ideas reconocidas plenamente en el campo de la investigación, tales como las redes o cartografías intelectuales, en el presente estudio la considero más adecuada, debido a que, si se recupera su sentido benjaminiano, también atiende a un sentido de originalidad. Considerando las características particulares del Ateneo Mexicano, tales como su carácter de asociación bisagra que entrelazó dos temporalidades al interconectar a consagrados y jóvenes, retomo la pregunta de Benjamin: "¿se trata en realidad de una extinción de la facultad mimética, o tal vez de una transformación que en ella misma ha tenido lugar?” (209). La conste-

${ }^{9}$ Sobre el sentido de una constelación en el ámbito literario, Fernando Curiel señaló que la luz de la constelación, incluso después de su entera extinción, orienta inevitablemente a su entorno. Belem Clark propone hablar de "constelaciones de intelectuales" y con ello su objetivo es "dar cuenta tanto del recorrido que los escritores hacían por los espacios de la ciudad de México", como "de su movilidad cultural" (16). De este modo, Clark ha destacado lo útil del término "constelaciones" por encima del método generacional, puntualizando que "el esquema generacional no considera la ubicación de los escritores según los parámetros literarios de su producción, o la misión que ellos mismos se impusieron o el círculo o camarilla a la cual entregaron, por coincidencia de intereses, su adscripción" (15). Por mi parte, para comprender la propia estructura de la "constelación" también retomo la organización generacional — siguiendo por ejemplo la propuesta de Luis González en La ronda de las generaciones-. Con ello me interesa comprender que la "constelación" está conformada a su vez por varias generaciones, identificando en el caso del Ateneo Mexicano a "jóvenes" y "consagrados". Asimismo, en mi planteamiento, integrando las reflexiones de Benjamin sobre el término, destaco el carácter de originalidad que anida en una constelación, es decir su carácter "aurático". 
lación, como una congregación de caracteres diversos, logra una experiencia irrepetible en el Ateneo Mexicano mediante una estructura taxativa de intersección de experiencia intergeneracional. Significa la asimilación de trayectorias multidisciplinarias y heterogéneas ideológicamente que se funden en un punto de cruce "aurático", que detona su autenticidad. La unión de intelectuales no solo diversos en disciplinas de estudio, sino también en posturas políticas, fundió propósitos o principios diversos guiados sobre una misma intencionalidad sociocultural, en su caso la producción y difusión de conocimiento guiado hacia una intervención social.

La empresa del Ateneo Mexicano originada en la década de 1840, como se profundizará en lo sucesivo, fue el programa más integral que llevó a cabo la generación de consagrados y la última de la primera mitad de siglo que reuniría a la intelligentsia de México en una arena de tregua sin distinción política, ni generacional. La orientación integral y pedagógica de sus actividades, respaldada por una revista que tuvo un carácter semioficial, dotó al grupo de una plataforma institucional a través de la cual los ateneístas preponderaron la producción de argumentos propios y, abordando problemáticas de interés sociocultural, posicionaron a la producción cultural como un importante vehículo moldeador de la opinión en el espacio público. En los años subsecuentes, la guerra de México con Estados Unidos (1847-1848) irrumpió proyectos, así como la vida pública en general. Finalmente, en la década de 1850, varios de estos personajes esenciales en la construcción institucional del México independiente enfrentaron un sentimiento de desilusión, deshonor y perjuicio (Tornel), otros fallecieron al inicio de la década de 1850, tal fue el caso de Mariano Otero (1850), Andrés Quintana Roo (1851), José María Tornel (1853), Juan Bautista Morales (1856) y Lucas Alamán (1853); otros, en cambio, se radicalizaron. Con base en lo anterior, la constelación cultural intergeneracional del Ateneo Mexicano representa un último momento culminante y de empoderamiento de lo cultural antes de la catástrofe de la guerra. 
Con base en lo aquí señalado, la constelación - como parte de un entramado mayor- marca un ritmo álgido ubicado en el propio entretejido progresivo de asociaciones y revistas literarias, todas semejantes pero diferentes, pertenecientes a un proceso o sistema de interacciones. De modo que la constelación como estrategia discursiva permite valorar una forma de mayor complejidad, es decir, su relevancia, que emana de su estructura taxativa, peculiar y original. Asimismo, estimula su análisis también con cortes transversales como parte de un entramado fundamental en el desarrollo histórico. Finalmente, como veremos en lo sucesivo, esta constelación intergeneracional y multidisciplinaria operó no solo en el debate intelectual y sociocultural de la primera mitad del siglo XIX, sino también en la formación de un aparato intelectual e institucional cultural de las épocas de la Reforma, Segundo Imperio y República Restaurada.

\section{LA FUNDACIÓN DEL ATENEO MEXICANO}

La organización del Ateneo Mexicano se llevó a cabo durante noviembre y diciembre de 1840. Participaron en ella personajes como José Gómez de la Cortina y Andrés Quintana Roo. Por su parte, aunque su presencia se delimitó a dicho momento de arranque, Ángel Calderón de la Barca, primer ministro español en México, sugirió la fundación del grupo, así lo refieren los propios miembros fundadores e incluso así lo asentó Calderón en su Diario. Finalmente, el 17 de enero de 1841 se verificó la "instalación pública de la sociedad". Bocanegra lo recordó como un acto "solemne" en el cual se congregó "numerosa asistencia de socios y de particulares" (802). La licencia fue otorgada por Miguel Valentín Canalizo, que para entonces fungía como jefe de gobierno de la Ciudad de México y quien fue designado como presidente de la asociación. Valentín Canalizo destacó de esta manera la utilidad de la empresa del Ateneo, enfocada en las ciencias y las artes: "en su conciencia hallan una resolución valedera, y cierta seguridad sostenida en sus rectas y eficaces intenciones de aplicar 
todas sus facultades para obtener su objeto, a saber: la comunicación y propagación de las luces en las ciencias y las artes". Cabe reiterar que, aunque Ángel Calderón de la Barca fue quien sugirió fundar el Ateneo y participó de su organización, entre noviembre y diciembre de 1840, durante estos meses su figura se diluyó casi en su totalidad. De este modo, con la intención de comprender cómo el grupo fue moldeando su propia empresa sociocultural mediante un discurso de exaltación nacional, he dividido su fundación en dos etapas: la de arranque, es decir, un breve periodo en el cual Calderón destaca como promotor de la asociación; y otra en la cual, ante su figura ya diluida destacan en lo sucesivo personajes como Andrés Quintana Roo y José Gómez de la Cortina, entre otros.

Ángel Calderón de la Barca arribó a tierras mexicanas el 18 de diciembre de 1839 en calidad de primer embajador de España asignado en México. Durante su estancia se propuso convocar, en torno a unas tertulias literarias, a lo más destacado de la intelectualidad mexicana. En su Diario asentó que había convocado a "una junta" "para formar el Ateneo Mexicano", como una asociación en la cual se discutirían temas exclusivamente literarios (Diario de Ángel Calderón 73). La reunión se llevó a cabo el 22 de noviembre de 1840 en la casa del Conde de la Cortina en Tacubaya, Ciudad de México (conocida hoy como "Casa de la Bola"). Ciertamente, tanto José María Bocanegra como Guillermo Prieto coinciden en sus Memorias en que Calderón fue una figura nodal en la fundación de la asociación literaria. Con gran ánimo se reunieron en la casa del ministro Calderón de la Barca para "formar el reglamento del Ateneo". Algunos de los ateneístas que tomarían las riendas de la asociación serían Quintana Roo y Gómez de la Cortina, Luis Gonzaga Cuevas y Pablo Vergara. ${ }^{10}$

${ }^{10}$ Calderón de la Barca, en su Diario, asentó "Luis Cuevas" y "Vergara". Al cotejar la lista de los ateneístas se deduce que se refiere a Luis Gonzaga Cuevas y Pablo Vergara. 
Entender que la figura del ministro español en el Ateneo Mexicano fue relevante y no obstante efímera resulta de vital importancia, debido a que, en primera instancia, su presencia como fundador podría contradecir el rumbo que tomó el grupo y su empresa literaria dirigida a "instruir a las masas". Bajo esta lógica, surge la pregunta: ¿cómo fue posible que una asociación literaria fundada por un ministro español en México haya promovido una empresa educativa a partir de un discurso nacionalista? Sobre lo anterior, es preciso subrayar que, si bien la convocatoria de Calderón de la Barca fue fundamental para la integración del grupo, su aportación se limitó solo a dar el banderazo de salida. El aspecto que determinó que la presencia del ministro se desvaneciera rápidamente fue que este no comulgó con el rumbo que tomaban las discusiones al interior del grupo. Al respecto, desde noviembre el ministro manifestó una profunda desilusión. Su queja consistía en que los objetivos "meramente" literarios de la asociación estaban tomando otra dirección. En este tenor, su participación no rebasó los dos meses. Para el 29 de noviembre, Calderón señaló en su Diario que en el grupo "Todo lo quieren hacer cosa de gobierno" y con desilusión señalaba: "Empieza a pesarme el haberme metido en esto" (Diario de Ángel Calderón 153). Asimismo, es de llamar la atención que el día en que se llevó a cabo la ceremonia formal del establecimiento de la asociación, el 17 de enero de 1841, Calderón no hizo ninguna descripción en su Diario (174).

Ciertamente, la creatividad literaria en México estaba impregnada de un discurso nacionalista. Recordemos que la Academia de Letrán había iniciado contundentemente esta tendencia en 1836 con su proyecto de "mexicanización de la literatura", proyecto al que, con otras soluciones, dio continuidad el Ateneo Mexicano. Por su parte, los ateneístas anunciaron que su grupo era el heredero directo del legado intelectual de la Academia de Letrán y, autoasumidos como portadores de sus postulados, se posicionaron abiertamente como preservadores de aquella tradición de la literatura mexicana, al tiempo que como su vanguardia: "nuestra época es la de la verdadera lite- 
ratura mexicana" (Lafragua 12). Esta estrategia de establecer un nexo intelectual pretérito, les permitió trazar coordenadas de una tradición "originaria" y reconocerse en generaciones predecesoras. Con base en este sistema de referencias, ubicaron el conocimiento heredado de la ilustración novohispana, incluyendo autores como Francisco Javier Clavijero (1731-1787), Francisco Javier Alegre (1729-1788), Juan Bautista Muñoz (1745-1799) y Alonso de Molina (1513-1519) (Lafragua 11); así como el traslado de esta herencia hacia la Academia de Letrán, de la cual se nutrían los propios ateneístas autodenominándose como la referencia más actual. Finalmente, el establecer a sus "precursores" como una "explicación de sí mismos" remite a la conciencia de una tradición ausente, ${ }^{11}$ y en su caso a la labor de su construcción; así como a una intención legitimadora de su presencia reciente en la escena mundial.

Contrario a los propósitos estrictamente literarios que Calderón de la Barca había planteado, el quehacer intelectual de los ateneístas, motivado también por el reconocimiento de una tradición literaria propia, se vio influido por el acontecer político que conocían de primera mano. México había caminado de desencanto en desencanto, experimentando distintos sistemas de gobierno, pasando por la monarquía, la república federal y el centralismo. En este sentido, en el país se experimentaba una inestabilidad política expresada también a través de incesantes pronunciamientos, lo cual, aunado a los conflictos de política exterior, como la pérdida de Texas (1835-1836) y la Intervención Francesa (1838-1839), ponía en riesgo la soberanía del país. ${ }^{12}$ La cultura y la instrucción, como ejes alternos de impac-

${ }^{11}$ Guillermo Zermeño reconoce esta operación como la fabricación de esta tradición en el ámbito intelectual hispanoamericano a principios del siglo XX (783).

${ }^{12}$ Para una genealogía de los pronunciamientos ver Forceful negotiations. The origins of the Pronunciamiento in Nineteenth-century Mexico de Will Fowler (University of Nebraska, 2010). 
to social, comenzaron a operar como importantes elementos para promover la unión e identidad nacional. Imbuidos en esta inercia, los ateneístas concibieron en la cultura un medio metapolítico que contribuyera a sortear estas dificultades de inestabilidad, de discordia política; se trataba de impulsar un nuevo orden a través de la instrucción de los ciudadanos (Madrigal, "El concepto" 22). En este sentido, el proyecto cultural del grupo coincide con los propios anhelos políticos relacionados con el concepto de cultura de la década de 1840; es decir, "el empeño de configurar un Estado moderno secular y promover un grado de instrucción entre la sociedad con el fin de conformar una base ciudadana" (Madrigal, "El concepto" 177). Asimismo, los ateneístas, con su empresa cultural, a la vez que propagaban conocimiento entre la sociedad, también ampliaban la base de hombres útiles, posicionando a la cultura como un elemento potenciador de movilidad social y de participación política.

Con base en lo anterior, la fundación del grupo representó para los ateneístas la oportunidad de organizar un "patriótico proyecto" (Gómez de la Cortina, "Introducción" 3), como ellos mismos lo denominaron. Así, mediante la exaltación de la utilidad de la instrucción, los ateneístas "deseosos de contribuir del mejor modo posible al progreso de las ciencias y de las artes" propusieron al gobierno departamental de la capital permitir establecer su asociación "cuyo objeto era la propagación de conocimientos útiles para la clase menesterosa y menos instruida" (Bocanegra 802). La experiencia en cargos públicos de los personajes cardinales en la organización y logística de la asociación permitió a los ateneístas ubicar problemas reales de carácter nacional y sistematizar determinadas estrategias de vinculación dirigidas a la organización y difusión de conocimiento entre la sociedad.

No obstante la participación efímera de Calderón de la Barca, no se puede perder de vista su aportación al grupo. Al respecto, se debe considerar que, para 1840, Calderón ya había participado como segundo secretario en el Ateneo Español de Madrid, fundado en su 
país en 1820. Además de su carrera diplomática, a Calderón se le reconoce su perfil humanístico, caracterizado por su aprecio y valor por el estudio de las letras y las ciencias. En este sentido, su trabajo se enfocó sobre los campos de la agronomía, la fotografía y la traducción en distintos idiomas, incluyendo el alemán, el francés y el inglés (Ruíz Salvador 18, 24).

Es un hecho que Calderón, cuando propuso a los intelectuales mexicanos conformar la asociación literaria, encontró inspiración en su experiencia como miembro del Ateneo de Madrid y que incluso pudo haber propuesto el mismo nombre. Sin embargo, a los ateneístas mexicanos no les interesó hacer una conexión del Ateneo Mexicano con el de Madrid. En su texto inaugural, el cual fue conducido sobre una exaltación de la literatura presuntamente nacional, se señaló que el nombre de "Ateneo" lo habían adaptado "a imitación del que fundó en Roma con igual objetivo el emperador Adriano, hacia el año 135 de la era cristiana". Señalaban que la asociación "debía reunir todas las ciencias y todos los talentos" por lo que "justo y oportuno fue darle el nombre de Ateneo Mexicano" (Gómez de la Cortina, "Introducción" 3).

Fue así que, en la primera etapa de la fundación del Ateneo Mexicano, Calderón de la Barca fungió como uno de los protagonistas de su organización, trazando una línea de partida y delimitando su carácter estrictamente literario; y en una segunda etapa se diluyó por completo su figura y tomaron la dirección otros ateneístas. Sobre el rumbo que tomó el grupo, si bien sus debates se desarrollaron desde un enfoque académico, los temas se plantearon con base en la realidad que vivía México como una nación recién independiente.

Finalmente, Calderón de la Barca —habiendo concluido su labor diplomática en agosto de 1841- entregó el cargo a su sucesor y en enero de 1842 partió a la Habana (Figueroa 112). Pese al escepticismo del ministro español, la asociación "pasó de diez años", "superando las esperanzas de muchos" (Bocanegra 802). Sin tener fecha exacta de la clausura de sus actividades, Bocanegra refiere que 
el Ateneo concluyó a "causa de los trastornos y revueltas" que sufría el país (802). Lo que en definitiva se observa en el devenir de la asociación es un paulatino desarrollo que comienza desde 1840, con la implementación de sus cátedras, lecturas y la instalación de una biblioteca pública y un gabinete de lectura. Asimismo, la publicación de su revista (1844-1845) materializó los debates llevados a cabo en su foro. Posteriormente, en 1846 el grupo todavía tuvo la facultad de convocar a un concurso literario, en el que ganó Francisco Ortega con su texto Memoria sobre los medios de desterrar la embriaguez: La Guerra de 1847 tuvo que haber marcado un declive en sus actividades hasta llegar a su clausura en 1850, fecha en la que se anunció la donación del mobiliario e instrumentos, que ya se encontraban en desuso, con los que los ateneístas habían impartido sus cátedras y lecturas públicas. Por esta razón, ese mismo año, el Liceo Hidalgo solicitó al entonces ministro de Relaciones, José María Lacunza, "conseguir el acuerdo necesario para disponer de los libros, pinturas, instrumentos y otros objetos que pertenecieron al Ateneo Mexicano" (Fondo de Justicia e Instrucción Pública, vol. 63). Como asentó Bocanegra, la asociación sobre la que se tuvieron pocas expectativas de vida, dada la polarización ideológica y las pugnas políticas, persistió una década, e incluso, de acuerdo con las noticias de varios periódicos, fue restablecida en 1851, anunciando su reapertura con la impartición de cátedras y la venta de su revista en la que muchos de los ateneístas habían reunido "composiciones de mérito" (El Siglo Diezy Nueve 4). Sin embargo, considerando que en esta primera etapa se engloba la trascendencia del grupo, este estudio se delimita a ella.

\section{EL ATENEO MEXICANO COMO UNA CONSTELACIÓN CULTURAL INTERGENERACIONAL}

La estructura del Ateneo Mexicano como una constelación cultural intergeneracional reunió a dos grupos claves en la historia de México, a quienes aquí denomino consagrados y jóvenes. La generación de los con- 
sagrados experimentó la guerra y la consumación de la Independencia, así como la consolidación de la nueva República; mientras que la de los jóvenes experimentó el proceso de Reforma.

La asociación como una constelación cultural intergeneracional, con una mayoría de los ateneístas consagrados, si bien operó durante la primera mitad del siglo XIX, también figuró como un semillero intelectual y cultural. Esto último fue posible debido a que incluyó a personajes literarios y políticos íconos de la segunda mitad de siglo, tales como Manuel Payno, Guillermo Prieto, Manuel Orozco y Berra, y Eulalio María Ortega, quienes incursionaron en el Ateneo Mexicano muy jóvenes, de manera que este fungió como parte de su formación.

El criterio que aquí empleo para clasificar a los integrantes, ya sea como consagrados o como jóvenes, fue primero la edad - ubicando como consagrados a los mayores de veinticinco años al momento de la fundación de la asociación-, seguida por su trayectoria y reconocimiento en los campos político y cultural, y por último su jerarquía en los puestos directivos de la asociación. De hecho, en la primera mitad del siglo XIX era bastante normal que entre los 25 y los 30 años de edad se alcanzara el clímax profesional ocupando carteras de Estado de alto nivel, como ministerios, senadurías o diputaciones. Lo anterior en gran parte se debió a que México, al ser un Estado joven que había conquistado su independencia tan solo un par de décadas atrás, no contaba con un cuerpo burocrático de carrera como el que existió en la última mitad de siglo de la Nueva España. De este modo, en las décadas posteriores a 1821, se abrieron espacios de inserción política, los cuales serían ocupados por aquella generación de la Independencia. Así, el foro del Ateneo Mexicano no solo congregó a los hombres de Estado encargados de construir las instituciones políticas y culturales de la nación recién independizada, sino que también contribuyó a moldear a la generación que se desempeñó en la segunda mitad de siglo. 


\section{LOS ATENEÍSTAS CONSAGRADOS}

Como he mencionado, el Ateneo Mexicano se conformó de una mayoría de ateneístas consagrados quienes, para la fundación del grupo en 1840, ya contaban con una amplia experiencia en los campos de la política y la cultura (ver Tabla 1).

Tabla 1. Lista de algunos de los ateneístas consagrados más representativos, con nombre y edad a la fecha de fundación del Ateneo. ${ }^{a}$

\begin{tabular}{|c|c|c|c|}
\hline Nombre & Edad & Nombre & Edad \\
\hline Juan de Orbegozo (1780-1846) & $(60)$ & José María Lafragua (1813-1875) & $(27)$ \\
\hline $\begin{array}{l}\text { Manuel [Antonio] Castro } \\
(1787-1854)\end{array}$ & (53) & Camilo Bros (1812-1888) & (28) \\
\hline Andrés Quintana Roo (1787-1851) & (53) & Pascual Almazán (1813-1885) & (27) \\
\hline José María Bocanegra (1787-1862) & (53) & Melchor Ocampo (1814-1861) & (26) \\
\hline Luis Gonzaga Cuevas (1799-1867) & $(41)$ & Manuel Payno (1810-1894) & $(30)$ \\
\hline $\begin{array}{l}\text { Ignacio Vera [y Lazcano] } \\
(1805 ?-1871)\end{array}$ & $(45)$ & $\begin{array}{l}\text { José Gómez de la Cortina } \\
(1809-1869)\end{array}$ & (31) \\
\hline José María Tornel (1795-1853) & $(45)$ & Manuel Larraínzar (1809-1884) & $(31)$ \\
\hline Manuel Carpio (1791-1860) & $(49)$ & José María Lacunza (1809-1869) & $(31)$ \\
\hline Isidro Rafael Gondra (1788-1861) & $(52)$ & \begin{tabular}{|l|} 
Pedro García Conde \\
$(1806-1851)$
\end{tabular} & (34) \\
\hline $\begin{array}{l}\text { Miguel Bustamante [y Septién] } \\
(1790-1844)\end{array}$ & (50) & Mariano Otero (1817-1850) & (31) \\
\hline Mariano Gálvez (1794-1892) & (46) & Lorenzo Hidalga (1810-1872) & $(30)$ \\
\hline Juan Bautista Morales (1788-1856) & $(52)$ & Luis de la Rosa (1804-1856) & (36) \\
\hline Francisco Ortega (1793-1849) & $(47)$ & Joaquín Cardoso (1803-1880) & $(37)$ \\
\hline Lucas Alamán (1792-1853) & (48) & $\begin{array}{l}\text { Francisco Modesto Olaguíbel } \\
\text { Martiñón (1806-1865) }\end{array}$ & (34) \\
\hline $\begin{array}{l}\text { Antonio Fernández Monjardín } \\
(1802-1870)\end{array}$ & (38) & \begin{tabular}{|l|} 
José Ramón Pacheco \\
$(1805-1865)$
\end{tabular} & (35) \\
\hline José Mariano Castillero (1790-?) & $(50)$ & Fernando Calderón (1809-1845) & $(31)$ \\
\hline José Joaquín Pesado (1801-1861) & (39) & $\begin{array}{l}\text { José Fernando Ramírez } \\
(1804-1871)\end{array}$ & (36) \\
\hline
\end{tabular}


Casi la totalidad de los ateneístas consagrados había contribuido a la organización institucional de México durante sus primeras décadas como país independiente, de modo que, para la década de 1840, el Ateneo Mexicano se observa como la decantación de aquellos proyectos previos. En el mismo sentido, el discernimiento de esta experiencia en la administración pública permitió a los ateneístas ubicar la "instrucción" como un aspecto fundamental para construir una base ciudadana, como un elemento esencial para el funcionamiento social (Gálvez 64-67, Espinosa 85). En este sentido, el grupo debatió temas conectados con problemas propios de la agenda nacional, que conocían a partir de su propia labor, debido a que ocupaban o habían ocupado los máximos puestos en el gobierno. El dominio de los consagrados también condujo al grupo hacia una postura ideológica moderada. Muestra de ello es su clara línea editorial apolítica, con base en la cual no se permitió la publicación ni de artículos con propaganda ideológica, ni de ningún tipo de arenga política. En este tenor, el 11 de diciembre de 1840 se reunieron los ateneístas para acordar los objetivos de la asociación y nuevamente el 20 de diciembre en el Colegio de todos los Santos, donde se asignó a la directiva: como presidente se nombró a Valentín Canalizo, como vicepresidente a José María Bocanegra y como secretario a Monjardín ("Anales del Ateneo" 240). Al respecto, ese mismo día, con un tono de indiferencia, Calderón de la Barca solo refirió en su Diario muy escuetamente: "Por la mañana al Ateneo -Quedó instalado; me nombraron conciliario-" (Diario de Ángel 167).

Una vez constituida la asociación, los ateneístas se propusieron entonces discutir los alcances de esta redactando su Reglamento y la Licencia de Ley. Cabe subrayar que este último fue el documento con el cual el grupo solicitó al gobierno de la Ciudad de México su consentimiento para establecer su asociación literaria. Parte de la originalidad del Ateneo Mexicano justamente radica en el carácter legal y formal sobre el cual el grupo cimentó y dirigió sus actividades, para lo cual los ateneístas concibieron: una Junta de Gobierno y un 
Reglamento que rigiera su organización. En el mismo sentido, destaca el respaldo oficial con la Licencia de Ley que otorgó el gobierno en turno para su fundación. Estas características marcaron una estructura diferente respecto a las asociaciones semejantes de su época, que potenció al Ateneo con un mayor impacto y reconocimiento en el espacio público.

Con base en lo que asentó el grupo en su Reglamento, se deduce que la asociación se autofinanció a partir de una cuota mensual que tenía que cubrir cada uno de sus miembros y no con recursos del gobierno. Fue solo hasta que cambió su sede al edificio que ocupaba la Universidad de México y el Museo Nacional cuando comenzaría dicho apoyo. Este último aspecto también remite a la dimensión sociocultural del "patriótico proyecto" del Ateneo. Al respecto, aunque los ateneístas no buscaron retribución económica por sus labores, sí persiguieron un reconocimiento, construyendo un legado como un organismo núcleo dentro de la infraestructura cultural de la nación mexicana en su temprana formación, asumiendo un compromiso social a través de su proyecto educativo de masas. Sobre el impacto del grupo, Anne Staples reconoce al Ateneo Mexicano entre las instituciones informales que incentivaron "la educación extracurricular" ofreciendo cátedras públicas y gratuitas. También se sabe que los instructores, que para 1840 se estaban formando en la Escuela Normal, tomaron sus clases de geografía en el Ateneo Mexicano $(68,413)$.

En la organización del Ateneo Mexicano en 1840 y en los años consecutivos, el grupo de los consagrados fue mayoritario y fue el que ocupó los puestos directivos. Asimismo, aquellos ateneístas consagrados también se mantuvieron a la vanguardia en el poder político. Justamente, su experiencia en la administración pública es un aspecto nodal para comprender que su empresa intelectual no solo tuvo una misión literaria y periodística, sino también pedagógica y social, dado que los temas que se debatían al interior del grupo estuvieron imbuidos de la propia experiencia de muchos de los ateneístas como dirigentes políticos y gestores culturales. Sobre los cargos que 
desempeñaban, cabe destacar que Valentín Canalizo, quien fungió como presidente del Ateneo Mexicano entre 1840 y 1842, era el Jefe del Departamento de México; mientras que José María Bocanegra, vicepresidente de la asociación, encabezaba el Ministerio de Relaciones Exteriores ("Expediente personal" 88-89). Los dos conciliares de la asociación, Ángel Calderón de la Barca y Andrés Quintana Roo, fungían, respectivamente, como ministro de España en México y como comisionado del gobierno para obtener la reincorporación de Yucatán, lo cual se lograría un año después, en 1841 (Menéndez). Los dos secretarios de la asociación, Antonio Fernández Monjardín y José María Lafragua, trabajaban en el Supremo Poder del país: el primero como presidente del Senado y el segundo como diputado al Congreso Constituyente (1842) por Puebla. ${ }^{13}$ Por último, el tesorero José Gómez de la Cortina se desempeñaba para entonces como presidente del Banco de Avío, fundado diez años antes por Lucas Alamán con el objetivo de fomentar la industria nacional. De modo que su participación como hombres de Estado les permitió trasladar problemas o necesidades del ámbito político y de la propia realidad social al debate académico; siendo su objetivo la "propagación de conocimientos útiles" a las clases menos instruidas. Fue en este sentido que una de las aportaciones más importantes del Ateneo Mexicano fue su empeño en la construcción de una ciudadanía. Esto es visible a través de los temas que abordó el grupo tanto en las cátedras como en su revista. ${ }^{14}$

${ }^{13}$ Antonio Fernández Monjardín (1802-1870) nació en Puebla, estudió en el Seminario Palafoxiano y se graduó de abogado en 1829. Se desempeñó como un distinguido jurisconsulto. Fue magistrado de la S. Corte de la Nación y presidente del Senado en 1838. Siendo socio fundador del Ateneo Mexicano ocupó el puesto de consiliario en 1841.

${ }^{14}$ Para el tema de la contribución del Ateneo Mexicano en la construcción de la ciudadanía, ver: Madrigal Hernández, Erika. The Ateneo Mexicano: the cultural 
De igual manera, los ateneístas consagrados al momento de fundar el Ateneo Mexicano, además de participar del acontecer político gozaban de una trayectoria como fundadores y gestores culturales. Sobre esto último, al momento de la fundación, Andrés Quintana Roo ya había cobijado otros proyectos literarios claves en la vida cultural de México, tales como la apertura del Instituto de Ciencias, Literatura y Artes, en 1823, así como la fundación de la Academia de Letrán en 1836, en la cual fungió como su mentor. Por su parte, José Gómez de la Cortina, quien permaneció en el Ateneo Mexicano hasta 1850, fue uno de los intelectuales más prolíficos. Para cuando tomó la batuta del Ateneo ya había dirigido la fundación de organismos de gran relevancia, como el Instituto Nacional de Geografía y Estadística en 1833, así como la Academia de la Lengua en México y la Academia de Historia en 1835. Otros ateneístas también destacaron en la organización de las ciencias y la cultura en el México independiente. Lucas Alamán, por ejemplo, organizó el Archivo General de la Nación y el Museo de Antigüedades e Historia Natural (1823). Por su parte, José María Tornel se desempeñó como vicepresidente de la Compañía Lancasteriana entre 1826 y 1851, con periodos intermitentes. Asimismo, su liderazgo como pieza clave en el sector educativo de México lo dotó de reconocimiento en el campo de las letras a lo largo de la primera mitad del siglo XIX.15

Para 1843 se observa un cambio en el organigrama de la Junta de Gobierno del Ateneo, la cual podría referir una lógica en el énfasis sobre la instrucción de las masas dado que la dirección del grupo

\footnotetext{
constellation of mid-nineteenth century Mexico, 1840-1850. 2019. University of St. Andrews, Tesis doctoral.

${ }^{15}$ No se debe perder de vista que Tornel, además de desempeñarse como ministro de Guerra, destacó sobre sus homólogos militares debido a que fue reconocido también en el mundo de las letras como un hombre ilustrado entre sus contemporáneos.
} 
que llevaba Canalizo, fue ocupada por José María Tornel, quien para entonces ejercía la dirección de la Escuela Lancastariana en México. ${ }^{16}$ Lo que es un hecho es que la fundación del Ateneo Mexicano y la propia misión que adoptó el grupo formó parte de un periodo de madurez y síntesis de proyectos previos en los que habían participado la gran mayoría de los ateneístas, quienes para entonces gozaban ya de una nutrida trayectoria en el ámbito cultural. De modo que el Ateneo Mexicano se observa como una constelación cultural que, a partir de la interconexión de agentes consagrados y jóvenes, esenciales en el desarrollo político y cultural, unió voluntades en torno a una empresa pedagógica de instrucción pública. En esta operación, el Ateneo Mexicano rompió con el modelo de tertulia privada, de logia masónica o bien de la academia enfocada en una instrucción especializada, por lo cual trascendió como promotora del conocimiento moderno entre un sector popular.

\section{LOS ATENEÍSTAS JÓVENES}

La generación de jóvenes fue integrada por ateneístas menores de veinticuatro años. Ellos habían crecido en las primeras décadas del México independiente, de modo que para la fecha de la fundación del Ateneo apenas comenzaba su trayectoria, tanto en el ámbito político como en el intelectual. Fue hasta el periodo de la Reforma cuando destacaron plenamente. En este pequeño grupo de jóvenes se encuentran: Casimiro del Collado (1822-1889) (18); Alejandro Arango y Escandón (1821-1883) (19); Guillermo Prieto (1818-1897)

${ }^{16}$ Para estudios sobre Tornel, ver: Fowler, Will. Tornel and Santa Anna. The writer and the caudillo, Mexico 1795-1853. Greewood Press, 2000; Vázquez Mantecón, María del Carmen. La palabra del poder. Vida pública de José María Tornel (17951853). UNAM / IIH, 2008. 
(22); Eulalio María Ortega (1820-1875) (20) y Manuel Orozco y Berra (1816-1881) (24). ${ }^{17}$ Asimismo, incluyo a Manuel Payno (18101894) (31) en este grupo, debido a que fue con esta generación con la que despuntó su carrera con plenitud. Todos ellos son reconocidos como protagonistas de la escena cultural durante la segunda mitad del siglo XIX.

En cuanto a la generación de los jóvenes y a los puestos que ocuparon al interior de la asociación, cabe señalar que solo cuatro años después de la fundación del Ateneo, en 1844, comenzó a destacar en labores directivas; sin embargo, en el grupo prevaleció el dominio y la autoridad de los consagrados. Ese año figuró Guillermo Prieto como segundo secretario en la Junta de Gobierno. Casimiro Collado hizo lo propio como secretario de la Sección de Redacción y Revisión. Eulalio María Ortega también se integró a aquella sección, mientras que Manuel Orozco y Berra se desempeñó como corresponsal.

La luz constelar del Ateneo que trascendió a través de los valores, actitudes y creencias plasmadas por los jóvenes ateneístas en el periodo de Reforma, se observa en la traslación de poder en los puestos del ámbito político y cultural que ocuparon. Asimismo, la labor de difundir el conocimiento en el ámbito público también tuvo continuidad, pues destacó su empeño en el diseño de libros de texto.

Guillermo Prieto, afiliándose al partido liberal, apoyó el Plan de Ayutla y se desempeñó como diputado en el Constituyente de 1857 y como defensor de esta durante la Guerra de Reforma. Acerca de la continuidad en la organización de la cultura y la educación, la aportación de Prieto fue su obra de carácter didáctico Breves nociones de economía política, así como otros dos trabajos enfocados en la enseñanza de la Historia: Breve introducción al estudio de la Historia Universal (1884) y Lecciones de historia patria, escritas para los alumnos del Cole-

${ }^{17} \mathrm{El}$ segundo paréntesis indica la edad de estos jóvenes al momento en que se estableció la asociación del Ateneo Mexicano. 
gio Militar (1886).${ }^{18}$ Sobre esta última, cabe destacar que obedece a la misma estructura que utilizó Gómez de la Cortina en sus Cartillas, con un contenido a manera de diálogo, con preguntas y respuestas breves y concisas. ${ }^{19}$

Manuel Payno fue varias veces diputado durante la República restaurada. En 1886 se le nombró cónsul en España y a su regreso en 1892 fungió como senador. En el plano intelectual se le reconoce su trabajo docente como profesor de historia en la Escuela Nacional Preparatoria (J. Vázquez). Entre sus textos de carácter didáctico destaca su Compendio de Historia de México (1870), el cual, al igual que la Cartilla Historial de Gómez de la Cortina, formó parte de los textos que aprobó la Compañía Lancasteriana de México como libro de texto oficial. No obstante su labor docente, Manuel Payno es principalmente reconocido por su obra literaria, en la que destacan sus novelas El Fistol del diablo (1846), ${ }^{20}$ El hombre de la situación (1861) y Los bandidos de Río Frío (1888-1891), siendo esta última la más famosa.

Por su parte, Orozco y Berra se desempeñó en el cargo de Secretario de Gobierno de su natal Puebla entre 1847 y 1848. Además, durante el gabinete de Ignacio Comonfort, fungió como Oficial Ma-

${ }^{18}$ Cabe señalar que en el ámbito de la cultura es bien conocida la labor de Prieto como crítico literario en sus famosos "San Lunes", de "Fidel" en El Siglo XIX, así como por la fundación del periódico satírico Don Simplicio (1845) junto con Ignacio Ramírez. Es reconocido también su trabajo como poeta popular y creador de cuadros de costumbres mexicanos, por el cual Manuel Altamirano le dio el título de "poeta nacional". Asimismo, su célebre obra Memorias de mis tiempos, que abarca de 1828 a 1853, es sin duda ya una obra clásica para conocer la vida cotidiana y retratos fidedignos de personajes claves de la época.

${ }^{19}$ Me refiero a Cartilla de historia o método para estudiar la bistoria (1829), CartiIla social o breve instrucción sobre los derechos y obligaciones del hombre en la sociedad civil (1836), Cartilla moral militar (1839).

${ }^{20}$ El Fistol del diablo fue publicada en la Revista científica y literaria de México en $1846 \mathrm{y}$, posteriormente, en 1859, fue publicada como libro. 
yor encargado del Ministerio de Fomento (1857). Una de sus empresas más importantes fue la colaboración en el Diccionario Universal de Historia y de Geografía (1853-1856), en la cual Manuel Orozco y Berra coordinó los tres tomos que conforman el Apéndice (1853-1856). En el mismo sentido, durante el Segundo Imperio, Orozco y Berra dirigió diversas comisiones de carácter científico. Asimismo, otro de los ateneístas jóvenes que durante el Segundo Imperio fue llamado a formar parte de la élite intelectual de Maximiliano fue Eulalio María Ortega, quien incluso llevó la defensa del archiduque Fernando Maximiliano de Austria frente al Consejo de Guerra, en el cual irremediablemente se le condenó a muerte (Memorandum sobre el proceso del Arcbiduque).

Regresando al organigrama con base en el cual se estructuró el Ateneo Mexicano, es importante mencionar que, en 1844, aunque los jóvenes se posicionaron en algunos puestos, los consagrados continuaron siendo predominantes en número y permanecieron como líderes en los cargos directivos: Isidro Rafael Gondra como bibliotecario, Mariano Otero como vicepresidente, Pedro Fernández del Castillo en calidad de primer consiliario, Benigno Bustamante como segundo consiliario, Lorenzo de la Hidalga como tesorero, José María Lafragua como primer secretario. De hecho, en la Junta de Gobierno de la asociación, el único joven que incursionó fue Guillermo Prieto como segundo secretario (Gómez de la Cortina, "Introducción" 9).

La fundación del Ateneo Mexicano como una constelación cultural intergeneracional significó una plataforma integral en la configuración de una cultura pública. Cabe reiterar que este fue un foro en el que brillaron por última vez algunos ateneístas consagrados, debido a que un número importante de estos personajes murió en los primeros años de la década de 1850. Visto desde este ángulo, el Ateneo Mexicano sería el último grupo de la primera mitad del siglo XIX que logró reunir a todos estos personajes, interconectando con su carácter de asociación bisagra dos temporalidades. 


\section{OBJETIVOS Y ALCANCES: “EL ESTUDIO ES UNA VERDADERA PANACEA"}

El Ateneo Mexicano publicó en su Reglamento que el objetivo del grupo era "propagar en el pueblo los conocimientos útiles, adquirir otros nuevos incesantemente para el mismo fin, fomentar las artes y la industria en nuestro suelo, y solazarse con el trato mutuo"; asimismo, subrayó que su objetivo era "promover la instrucción de las masas" (Reglamento 27). Con base en esto, el Ateneo se propuso inaugurar una nueva modalidad en la enseñanza: 1) estableciendo "la instrucción en muchos ramos de las ciencias [de la] que habían carecido" hasta ese momento la gran mayoría de los habitantes de México, lo cual sería posible, 2) considerando "los métodos más modernos de Europa" y 3) adecuando el contenido y el método de acuerdo a los "intereses privados" tanto del Ateneo como de los solicitantes (Reglamento 27).

La Junta de Gobierno organizó los campos de conocimiento en 20 secciones (ver Tabla 2). Así, el objetivo de los ateneístas de promover una educación gratuita fue puesto en práctica con base en un carácter multidisciplinario y con una dimensión sociocultural.

\begin{tabular}{|ll|}
\hline Tabla 2. Secciones en que está dividido el Ateneo, y socios que las presiden. \\
\hline SECCIONES & PRESIDENTES \\
\hline 1.- De redacción y revisión & D. José María Lafragua \\
\hline 2.- De jeografia y estadística & D. Pedro García Conde \\
\hline 3.- De literatura & D. Andrés Quintana Roo \\
\hline 4.- De lejislacion & D. Mariano Otero \\
\hline 5.- De industria & D. Mariano Gálvez \\
\hline 6.- De idiomas & D. Camilo Bros \\
\hline 7.- De ciencias morales & D. Ignacio Vera \\
\hline 8.- De ciencias naturales & D. Miguel Bustamante \\
\hline 9.- De ciencias militares & D. José María Tornel \\
\hline 10.- De economía política & D. Juan Bautista Morales \\
\hline 11.- De dibujo lineal y arquitectura & D. Lorenzo Hidalga \\
\hline
\end{tabular}




\begin{tabular}{|ll|}
\hline 12.- De dibujo natural & D. Jesús Corral \\
\hline 13.- De lengua castellana & D. José G. de la Cortina \\
\hline 14.- De historia & D. José María Lacunza \\
\hline 15.- De agricultura & D. Isidro Rafael Gondra \\
\hline 16.- De fomento & D. Pablo Vergara \\
\hline 17.- De instrucción primaria & D. Rafael Espinosa \\
\hline 18.- De ciencias médicas & D. Manuel Carpio \\
\hline 19.- De matemáticas & D. Manuel Castro \\
\hline 20.- De música & D. Rafael Palacios \\
\hline $\begin{array}{l}\text { a. Fuente: El Ateneo Mexicano. Omnium Utilitati. Tomo I, Imprenta de Vicente G. Torres, } \\
\text { 1844, pp. 7-8. }\end{array}$ \\
\hline
\end{tabular}

Como he señalado, en el transcurso entre la Academia de Letrán y el Renacimiento emergió un número importante de asociaciones y de revistas literarias. Ciertamente, todas estas compartieron con el Ateneo Mexicano el objetivo de forjar una nación a través de las letras y reunieron a personajes líderes en el campo de la política y de la cultura. Sin embargo, el Ateneo Mexicano representó una innovación frente a las asociaciones y revistas contemporáneas debido al carácter semioficial de su empresa, al apoyo legal que recibió su fundación y a su programa que incluyó seis recursos de vinculación social: revista literaria, lecturas y cátedras públicas, biblioteca, gabinete, así como una convocatoria a concursar con obras literarias al público en general. Todos estos medios fueron sistematizados para instruir a la sociedad. Con sus actividades, el grupo dejó atrás el formato de cenáculo intelectual cerrado y como contraparte confirió un carácter público a la organización y difusión del conocimiento.

El propio grupo exaltó de igual manera la gratuidad de sus actividades, incluidos gratuitamente los "libros elementales y utensilios más necesarios en cada ramo" (Gómez de la Cortina, "Introducción" 8). Esto nos habla de la consideración que los ateneístas tuvieron por sectores sociales antes descuidados. Con base en este proyecto integral, su mayor logro fue plantear las bases de una cultura pública con 
una dimensión sociocultural, el cual se direccionó hacia la organización, difusión del conocimiento útil e instrucción de las masas, con el cual el grupo promovió la formación de ciudadanos. De este modo, nociones como las de hombre moral, hombre físico, ciudadano, sociedad civil, virtudes y vicios del ciudadano fueron conceptos que se discutieron dentro y fuera del grupo. Dentro del Ateneo Mexicano también Mariano Otero, Melchor Ocampo e Ignacio Vera guiaron sus reflexiones acerca de los derechos y deberes legales y morales del ciudadano. Al respecto, es importante destacar que incluso antes de que se reunieran en la asociación literaria, uno de los pilares del grupo, José Gómez de la Cortina, ya había presentado especial interés sobre estos asuntos. Para la fecha en que se fundó el Ateneo Mexicano, Gómez de la Cortina ya había escrito sus Cartilla de Historia, Cartilla Social y Cartilla Moral, abordando temas sobre los límites de la libertad social, el bienestar social, así como los derechos y obligaciones del ciudadano. ${ }^{21}$

Inicialmente las actividades que pusieron en marcha los ateneístas fueron organizadas en un edificio ubicado inicialmente en la calle de Espíritu Santo número 8 (actualmente Isabel la Católica) espacio que abrió "todos los días desde las nueve de la mañana hasta las tres de la tarde, y desde las seis de ésta hasta las nueve de la noche" (Reglamento 4). Para el buen funcionamiento de sus cátedras, lecturas, biblioteca pública y gabinete el Ateneo invirtió fondos en "la compra de periódicos nacionales y extranjeros; obras de artes; ciencias y literatura; mapas, instrumentos de física y de química; y enseres para el surtido de las cátedras." (Reglamento 5) A continuación explicaré cada uno de los instrumentos de su proyecto.

${ }^{21}$ Para el tema de la contribución del Ateneo Mexicano en la construcción de la ciudadanía ver: Madrigal Hernández, Erika. The Ateneo Mexicano: the cultural constellation of mid-nineteenth century Mexico, 1840-1850. 2019. University of St. Andrews, Tesis doctoral. 
La revista El Ateneo Mexicano. Omnium utilitati, que publicó la propia asociación entre 1844 y 1845, reunió más de 100 textos sobre diferentes materias. La gran mayoría de los textos publicados fueron las propias cátedras y lecturas públicas que se impartían semanalmente en la sede del Ateneo. La publicación de la revista también representó una innovación y adelanto sobre las revistas contemporáneas, debido a su carácter enciclopédico y a que la gran mayoría de los textos fueron de la autoría de los propios ateneístas. Esto representó un gran avance, debido a que lo acostumbrado y común en la época era que las revistas se abastecieran de traducciones o reseñas de libros. Aunque no se cuenta con el dato del tiraje de esta publicación, la asociación planteó que se publicaría quincenalmente y posteriormente - cuando todas las secciones se hubieran regularizado- semanalmente. Su costo fue de entre tres a cinco reales en plata. La visión pedagógica de la revista estuvo dirigida a la formación de valores sobre los límites del poder, el compromiso y responsabilidad social, que podemos resumir como las bases de una educación cívica, orientada a moldear ciudadanos a partir de la instrucción y la cultura. ${ }^{22}$

Además de la impartición de cátedras y lectura públicas, los ateneístas organizaron y pusieron a disposición del público una colección abastecida por libros provenientes de la biblioteca del Estado de México. Esto se ratificó a través de un decreto enviado al gobernador del Departamento de México Luis Gonzaga Vieyra en 1841 (Fondo de Justicia e Instrucción Pública, vol. 45). La biblioteca también contó con un archivo que incluyó periódicos y papeles impresos sueltos. Isidro Rafael Gondra organizó la colección por índice y la encuadernó por

${ }^{22}$ Para estudios que abordan el papel de la intelectualidad en la formación de ciudadanos y en la educación cívica, ver: Ríos Zuñiga, Rosalina. Formar ciudadanos. Sociedad civily movilización popular en Zacatecas, 1821-1853. UNAM / Plaza y Valdés, 2005; Estrada, Dorothy T. Independencia y educación: cultura civica, educación indigena y literatura infantil. El Colegio de México, 2013). 
volúmenes. La donación de dicha biblioteca también alude al carácter semioficial del Ateneo Mexicano, aspecto que, como he mencionado, dotó al grupo de un carácter institucional que lo hizo gozar de algunos beneficios gubernamentales y, por ende, distinguirse en su tránsito, en la década de 1840, sobre otras asociaciones. En el mismo sentido, dicha donación ilustra la manera en que la clase gobernante paulatinamente se posicionó en la organización cultural y educativa. El Gabinete de lectura público fue otro de los medios a los que el Ateneo Mexicano recurrió para contribuir con la instrucción del pueblo. Este tipo de organismo - reconocido desde el periodo colonial - estuvo destinado tanto a instruir, como a socializar; los visitantes acudían para conocer colecciones naturalistas, así como de libros. De hecho, cuando la sede del Ateneo Mexicano es reubicada en el edificio de la Universidad de México, al gabinete de lectura se le asignará el aula contigua al Museo Nacional, también alojado ahí. No es casual la asignación del inmueble universitario para alojar al Ateneo, posicionándolo como una pieza clave en el panorama intelectual nacional, junto a la Universidad y al Museo Nacional. Justamente, Pedro Vélez, ministro de Justicia e Instrucción, en su comunicado subrayó que dada "la importancia del establecimiento literario, denominado: 'Ateneo Mexicano", la asociación merecía "la protección del supremo gobierno", dando con ello constancia de la distinción de la que gozó el Ateneo Mexicano como una asociación clave en la organización cultural y educativa de México y de su relación con las autoridades gubernamentales (Vélez 3).

En este contexto de la construcción de México como un Estado moderno secular, el Ateneo Mexicano constituyó un dispositivo pedagógico de instrucción de masas semioficial, incluyendo sus cátedras y lecturas públicas que se abrieron a un público en general, destacando la inclusión de normalistas. Fue así que el Ateneo participó de manera activa en este reordenamiento político y de transformación social, en el cual el ámbito educativo fungió como un promotor de orden y bienestar social, en un periodo en el cual la cultura se po- 
sicionó como un importante eje secularizante (Madrigal, "El concepto de cultura" 187).

El Ateneo Mexicano estableció sus cátedras y lecturas públicas con base en los 20 campos de conocimiento que he mencionado arriba. Aunque no se tiene constancia de la asistencia de las actividades del Ateneo Mexicano, estas fueron difundidas en diferentes periódicos como La Hesperia, El Siglo XIX y El Cosmopolita. Por estos medios se dio cuenta de los horarios de sus lecciones, los reglamentos de sus propias cátedras y el lugar de venta de los libros de textos de sus materias. De acuerdo con los ateneístas, sus cátedras estuvieron "rodeadas de una multitud de personas de todas edades, estados y condiciones que voluntariamente acuden a adquirir en aquel establecimiento los medios de aplicar el ingenio a las artes, a las ciencias y a las Bellas Artes" (Gómez de la Cortina, "Introducción” 5). De este modo y considerando lo desalentador del contexto político y social, los ateneístas concebían dichas cátedras como un "espectáculo tan consolador", reiteraban la idea de que "el estudio es una verdadera panacea", debido a que "la verdadera instrucción, el amor al trabajo y las luces necesarias [son útiles] para conocer nuestros deberes y asegurar la felicidad posible en esta vida" (Gómez de la Cortina, "Introducción" 5).

En síntesis, sobre las particularidades de la organización del Ateneo destacan la legalidad de su organización interna regida por su Reglamento, así como el respaldo institucional con la Licencia de Ley que le otorgó Canalizo. Asimismo, destaca su plataforma integral de instrucción pública, la instrucción de normalistas, así como el diseño de los textos de Gómez de la Cortina que se utilizaron como libros de textos en las Escuelas Lancasterianas. Por tanto, su propuesta de la educación como una panacea se inserta como importante agente en la construcción de una sociedad en un Estado moderno secular. Finalmente, la originalidad de la constelación cultural intergeneracional del Ateneo Mexicano - como un dispositivo pedagógico de instrucción de masas semioficial— se cimentó sobre las seis estrategias de vincu- 
lación social y extensión popular del conocimiento, que incluyeron cátedras, lecturas, biblioteca, gabinete, la publicación de su propia revista, así como la convocatoria a concursos literarios, todas abiertas a un público general, con lo cual su aportación permeó no solo el ámbito pedagógico y editorial, sino también el periodístico y científico.

\section{LA INSTRUCCIÓN DE LAS MASAS COMO CAPITAL CULTURAL}

El Ateneo Mexicano señaló en su Reglamento que su "fin principal" era "promover la instrucción de las masas" utilizando el término en plural. ¿A qué masas se referían? Si consideráramos el término de "masas" a partir de su significado actual, entendido como "fenómeno de masas", es decir como "un conjunto de personas sin distinción de grupos o individuos," ${ }^{, 3}$ entonces podríamos asentar que el proyecto de "instrucción de masas" que se propuso el grupo no se logró. Podría considerarse así puesto que las actividades de los ateneístas se dirigieron solo a algunos sectores y gremios circunscritos a la Ciudad de México, sin lograr desplegarse como un "fenómeno de masas" inconmensurable a lo largo de toda la República Mexicana. Sin embargo, en la primera mitad del siglo XIX, en el uso del término "masas" había una distinción entre su significado en plural, el cual se refiere a colectivos o grupos diversos, y en singular, que hace referencia a un cuerpo total de individuos, por ejemplo, una nación o una sociedad. ${ }^{24}$

${ }^{23}$ Estas personas como un "fenómeno de masas", en su calidad de "masa", se convierten en individuos indiferenciados, despojados de su sentido de "miembros" o personas concretas de grupos sociales (Enciclopedia Internacional de las Ciencias Sociales 777).

${ }^{24}$ Acerca de los distintos textos en los que se hacen evidentes las diferen- 
Con base en lo anterior, los ateneístas, en el texto de presentación de su revista, indicaron que aquellas "masas" a quienes dirigían sus actividades culturales eran los comerciantes, artesanos, agricultores y, en muchos casos, la propia servidumbre de los asistentes que no sabía leer ni escribir. Estas masas, es decir, cada uno de estos gremios, que conforman parte de una masa (social en su totalidad), fueron los grupos que asistieron a sus cátedras, lecturas públicas y otras actividades que emprendieron.

Los conceptos que utilizaron los ateneístas para declarar las expectativas de su empresa de instrucción fueron pueblo y masas, los cuales son de menor extensión que sociedad, nación y masa; dado que estos tres últimos refieren a una totalidad, como una suma completa. Justamente, José Gómez de la Cortina, en su Diccionario de sinónimos castellanos publicado en 1845, aunque no incluyó el término masas, hizo la distinción entre los conceptos nación y pueblo, acotando una diferencia de mayor y menor extensión en su significado: "la palabra colectiva nación comprende a todos aquellos que tienen el mismo nacimiento, que son oriundos del mismo país. Pueblo designa una gran multitud, un gran número" (111). Partiendo de este razonamiento, podríamos sugerir que el objetivo medular del grupo de "instruir a las masas", al "pueblo", es decir, a un gran número de colectivos o gremios, sí fue realizada, en tanto que los ateneístas abrieron sus debates intelectuales justamente a un público general, incluyendo como parte de estas masas a la ciudadanía en general, así como a los gremios de comerciantes, artesanos y agricultores.

Así, en el contexto en el que los ateneístas se propusieron "instruir a las masas", esta idea se refirió a popularizar la educación entre las masas, entre el pueblo, es decir, entre "una gran multitud, un gran número". Al

cias de uso de "masas" vs. "masa", ver: Madrigal Hernández, Erika. The Ateneo Mexicano: the cultural constellation of mid-nineteenth century Mexico, 1840-1850. 2019. University of St. Andrews, Tesis doctoral. 
momento que el Ateneo Mexicano anunció su "patriótico proyecto" de carácter multitudinario, las asociaciones literarias se habían dirigido a una pequeña clase privilegiada que hasta entonces era la que tenía acceso a las discusiones intelectuales, logias o academias especializadas. Por su parte, el Ateneo Mexicano transformó estos formatos, conduciendo su foro hacia la popularización de la educación.

La misión que asumió el Ateneo Mexicano en el ámbito intelectual fue la instrucción a un público amplio para "inspirar con ella las virtudes". En este sentido, los "progresos de la literatura influirán poderosamente en que se mejore la condición física del hombre y que se depure su corazón" (Gómez de la Cortina, "Introducción” 5). Los ateneístas incluso exponían como un ideal que la literatura contrarrestaría el "sentimiento de perversidad y de toda propensión a la barbarie" (Gómez de la Cortina, "Introducción” 5). No debe perderse de vista que, no obstante que el proyecto cultural tuvo un carácter público y que el propio grupo señaló que iba dirigido principalmente a la clase "menesterosa", lo cierto es que los ateneístas delimitaron su plan de acción incluyendo como su potencial público principalmente a una clase media activa económicamente y por lo tanto potencialmente activa también en el plano político. Es un hecho que los ateneístas concibieron que, con su empresa cultural, además de propagar su conocimiento entre la sociedad instruyéndola, también acrecentaban la base de hombres útiles.

Con base en lo anterior, es posible sugerir que, con la unificación nacional que proponían los ateneístas a través de la instrucción pública, también se construyó un capital cultural, en el sentido que lo propone Pierre Bourdieu: como un tipo de capital inserto en la lucha del poder político que confiere una fuerza de movilización y de poder público. Aquellos hombres ilustrados que habían sido agentes constructores de los primeros proyectos nacionales, involucrados ahora en el Ateneo, argüían que los hombres instruidos representaban también un capital social en el sentido de que potenciaban el propio bienestar del Estado. 
En este tenor, los ateneístas se mostraban conscientes de que una provechosa dinámica política emanaba del conocimiento. Recordemos que los ateneístas consideraban que el Estado podía fortalecerse y "sacar partido de los hombres" en la medida en que estos poseyeran un conocimiento cívico y moral básico (Gómez de la Cortina, "Introducción” 4). De manera inversa, para José María Lacunza, “el gobierno, el espíritu de los pueblos, [y] todo aquello que constituye un siglo y una nación, tiene un influjo directo sobre las ciencias" (229). Por su parte, Isidro R. Gondra también fue contundente acerca del papel crucial de la instrucción para un país, señalando que "[l]a educación sobre todo, es el agente más eficaz y poderoso, y tal vez el único capaz de acelerar la ilustración de un país" ("Introducción” 11).

Finalmente, un logro que define a la empresa intelectual del Ateneo Mexicano fue la plataforma integral de instrucción sociocultural en la que organizó, sistematizó y divulgó la cultura a través de distintos medios, como las cátedras y lecturas públicas, una biblioteca pública, un gabinete, así como la publicación de su revista y concursos literarios, todo ello con el fin de popularizar el conocimiento entre el público general. Todos estos medios fueron habituales para difundir las ciencias y las humanidades en aquel periodo. Sin embargo, en su empresa cultural, el Ateneo Mexicano sistematizó simultáneamente todos estos medios y los dirigió hacia una intervención social. De este modo, el grupo logró llegar a nuevos sectores que se encontraban ya sea marginados o bien con posibilidades limitadas de una educación media superior.

\section{CONCLUSIONES}

La constelación cultural del Ateneo Mexicano como una asociación intergeneracional y multidisciplinaria tuvo un carácter predominantemente pedagógico con una dimensión sociocultural. La asociación operó no solo en el debate intelectual, tanto en la formación de un aparato intelectual e institucional cultural, sino también como un gru- 
po generador de un nuevo orden en el ámbito político. Rompió con el modelo de tertulia cerrada o delimitada exclusivamente a una élite que predominaba en ese momento, promoviendo una intervención social a través de la instrucción. Fue así que, a partir de su plataforma institucional, el grupo promovió la creación de una base ciudadana a través de su programa de instrucción de las masas, propiciando a su vez el empoderamiento de la cultura en el espacio público.

$\mathrm{Su}$ aportación en la propagación de conocimiento moderno como una constelación cultural intergeneracional y multidisciplinaria se extendió al ámbito pedagógico, editorial, periodístico y científico. Además de las características propias de su organización integral y su funcionamiento institucional que dotaron de originalidad al Ateneo Mexicano y le dieron preeminencia, la propia trayectoria de los ateneístas consagrados, quienes participaron de la organización y dirección de las instituciones culturales y administrativas más importantes del México independiente, clarifica en qué medida el Ateneo Mexicano encarnó un periodo de madurez y auge en la organización de la cultura en la primera mitad de siglo. Asimismo, el Ateneo fue uno de los últimos grupos que alcanzó a congregar a un número importante de estos ateneístas consagrados.

En esta trayectoria de construcción de infraestructura cultural, como se mencionó, el Ateneo Mexicano figura como una asociación bisagra que entrelazó dos temporalidades representadas por dos grupos generacionales: la Academia de Letrán y el Renacimiento. Así, la empresa del Ateneo significó el discernimiento y absorción de proyectos previos en los que habían participado muchos de los ateneístas consagrados, así como un espacio de diálogo con la generación de jóvenes que trascenderían en la segunda mitad de siglo como hombres de Estado y cultura.

En un periodo de inestabilidad y pugnas políticas, el Ateneo Mexicano - como un grupo heterogéneo ideológicamente y al mismo tiempo como una arena neutral- repercutió en un espacio de empoderamiento cultural. Asimismo, la cultura como un capital po- 
lítico se posicionó en el espacio público como un vehículo para impulsar un nuevo orden desde el campo de la instrucción y organización del conocimiento. Aunque, las actividades del Ateneo dirigidas a instruir a las masas resultaron truncadas por la guerra de México con Estados Unidos, lo cierto es que su programa de carácter integral fue puesto en práctica y su legado cultural permanece.

\section{BIBLIOGRAFÍA}

"Anales del Ateneo, acta de la sesión del día 20 de diciembre de 1840”. El Ateneo Mexicano. Omnium Utilitati, tomo I, Imprenta de Vicente G. Torres, 1844.

Benjamin, Walter. "Doctrina de lo semejante". Obras, libro II, vol. 1, Abada Editores, 2016.

Bobadilla Encinas, Gerardo. Estudios sobre literatura mexicana del siglo XIX. Reflexiones críticas e historiográficas. Editorial Pliegos, 2009.

Bocanegra, José María. Memorias para la historia de México independiente. 1822-1846. Tomo II, Fondo de Cultura Económica / Instituto Helénico / Instituto Nacional de Estudios Históricos de la Revolución Mexicana, 1987.

Bourdieu, Pierre. Capital cultural, escuela y espacio social. Siglo XXI editores, 2011.

Calderón de la Barca, Ángel. Diario de Ángel Calderón de la Barca, primer ministro de España en México: incluye sus escalas en Cuba. Edición, notas, estudio introductorio y epílogo por Miguel Soto, SER / Southern Methodist University / William P. Clements Center for Southwest Studies, 2015.

Calderón, Fernando. Obras poéticas de don Fernando Calderón. $2^{\mathrm{a}}$ ed., prólogo de José Joaquín Pesado, impresas por el editor, Calle de los rebeldes núm. 2, 1850 .

Canalizo, Miguel Valentín. "Discurso de apertura". La Hesperia, 23 ene. 1841. 
Campos, Marco Antonio. La Academia de Letrán. Universidad Nacional Autónoma de México, 2004.

"Carta de Ramón Luna dirigida a Mariano Otero, Guadalajara, 30 de agosto de 1844". Los caminos de la justicia en los documentos de Mariano Otero, compilado por Marcia Jiménez Lavín, Suprema Corte de la Justicia de la Nación, 2011.

Clark de Lara, Belem, y Elisa Speckman Guerra, editoras. La República de las letras asomos a la cultura escrita del México decimonónico. Ambientes, asociaciones y grupos. Movimientos, temas y géneros literarios. Vol.1, Universidad Nacional Autónoma de México, 2005.

Clark de Lara, Belem. “¿Generaciones o constelaciones?”. La República de las letras asomos a la cultura escrita del México decimonónico, vol.1, editado por Belem Clark de Lara y Elisa Speckman Guerra, Universidad Nacional Autónoma de México, 2005.

- Hacia una historia del Liceo Hidalgo y la construcción de la literatura mexicana. Universidad Nacional Autónoma de México, 2017.

Curiel, Fernando. Elementos para un esquema generacional aplicable a cien años de literatura patria. UNAM, 2001.

El Ateneo Mexicano. Omnium Utilitati. Tomos I y II, Imprenta de Vicente G. Torres, 1844 y 1845.

El Siglo Diezy Nueve, México, 1851.

Enciclopedia Internacional de las Ciencias Sociales. Ediciones Aguilar, 1979. Espinosa, Rafael. "Instrucción primaria”. El Ateneo Mexicano. Omnium Utilitati, Tomo I, Imprenta de Vicente G. Torres, 1844.

Estrada, Dorothy T. Independencia y educación: cultura civica, educación indígena y literatura infantil. El Colegio de México, 2013.

"Expediente Personal, José María Bocanegra". Archivo Histórico de la Secretaría de Relaciones Exteriores, expediente LE-367, folios 88-89. Fondo de Justicia e Instrucción Pública. Archivo General de la Nación, vol. 63, expediente s/n, fojas 12-19.

Fondo de Justicia e Instrucción Pública. Archivo General de la Nación, vol. 45, expediente 42, fojas 308-312. 
Figueroa, Raúl. “Ángel Calderón de la Barca, diplomático español (1790-1861). Notas biográficas". Estudios 22, 1990.

Fowler, Will. Forceful negotiations. The origins of the Pronunciamiento in

Nineteenth-century Mexico. University of Nebraska, 2010.

. Tornel and Santa Anna. The writer and the caudillo, Mexico 1795-

1853. Greewood Press, 2000.

Gálvez, Mariano "Escuela nacional de agricultura: su plan de estudios, y observaciones relativas". El Ateneo Mexicano. Omnium Utilitati, Imprenta de Vicente G. Torres, 1844, T I, pp.64-67.

Gómez de la Cortina, José. "Introducción”. El Ateneo Mexicano. Omnium Utilitati, Imprenta de Vicente G. Torres, 1844, T I.

- Diccionario de sinónimos castellanos. Imprenta de José García Torres, 1845.

Gondra, Isidro R. "Introducción”. Semanario de las Señoritas Mexicanas, tomo I, 1840.

Justicia e Instrucción Pública. Archivo General de la Nación, vol. 63, fojas 12-19.

"Lista de los individuos que componen el Ateneo". El Ateneo Mexicano. Omnium Utilitati, tomo I, Imprenta de Vicente G. Torres, 1844, p. 262.

Lafragua, José María. "Carácter y objeto de la literatura”. El Ateneo Mexicano. Omnium Utilitati, tomo I, Imprenta de Vicente G. Torres, 1844.

Lafragua, José María, y Orozco y Manuel Berra. La ciudad de México. Porrúa, 2014.

Lacunza, José María. "Las ciencias y el siglo XIX”. El Ateneo Mexicano. Omnium Utilitati, tomo I, Imprenta de Vicente G. Torres, 1844.

Madrigal Hernández, Erika. "El concepto de cultura en México (1840-1846). Distinciones y disrupciones en contexto". Ariadna Histórica. Lenguajes, conceptos, metáforas, no. 9, 2020, https://ojs. ehu.eus/index.php/Ariadna/article/view/22172.

. The Ateneo Mexicano: the cultural constellation of mid-nineteenth century Mexico, 1840-1850. 2019. University of St. Andrews, Tesis doctoral. 
Martínez, José Luis. La expresión nacional, letras mexicanas del siglo XIX. Universidad Nacional Autónoma de México, 1955.

Martínez Luna, Esther. Dimensiones de la cultura literaria en México (1800-1850). Modelos de sociabilidad materialidades, géneros y tradiciones intelectuales. Universidad Nacional Autónoma de México, 2018.

Memorandum sobre el proceso del Archiduque Fernando Maximiliano de Austria. Biblioteca Nacional de México, Colección Lafragua, 1867, https://repositorio.unam.mx/contenidos/memorandum-sobre-el-proceso-del-archiduque-fernando-maximiliano-de-austria -3162 ? $c=4 b b X v 4 \& d=$ false $\& \mathrm{q}=* * * i=1 \& \mathrm{v}=1 \& \mathrm{t}=$ search _0\&as $=0$.

Menéndez, Carlos R. La fracasada reincorporación de Yucatán a México en 1841. Compañía tipográfica Yucateca, S. A., 1939.

Mora, Pablo. "Revistas científicas y literarias (1826-1856): notas y revisión de fuentes". Literatura mexicana 6, no.1, 1995, pp. 1-26.

Ortega, Francisco. Memoria sobre los medios de desterrar la embriaguez por el Señor Francisco Ortega, presentada en 30 de abril de 1846, y premiada en el concurso abierto por convocatoria del Ateneo Mejicano de 16 de noviembre de 1845, y promovido por el Señor D. Francisco Fagoaga, a cuyas expensas se imprime. Ignacio Cumplido, 1847.

Perales Ojeda, Alicia. Asociaciones literarias mexicanas: siglo XIX. Universidad Nacional Autónoma de México, 2000.

Reglamento del Ateneo Mexicano. Aprobado por la junta de gobierno en el año de 1843. Disponible en la Biblioteca del Seminario Conciliar de México.

Ríos Zuñiga, Rosalina. Formar ciudadanos. Sociedad civil y movilización popular en Zacatecas, 1821-1853. Universidad Nacional Autónoma de México / Plaza y Valdés, 2005.

Ruedas de la Serna, Jorge. La formación de la literatura nacional (18051850) Prolegómenos y Los cimientos del sistema. Tomos I y II, Universidad Nacional Autónoma de México, 2010.

Ruiz Castañeda, María del Carmen. "El Ateneo Mexicano. Omnium Utilitati. Órgano de la Asociación del mismo nombre (1844- 
1845)." Ciencias y desarrollo, 24, no. 138, enero-febrero (1998), pp. 65-71.

. "Contenido científico en las revistas literarias mexicanas del siglo XIX”. Revista de la Universidad de México, no. 548, sept. 1996. Ruiz Salvador, Antonio. El Ateneo científico, literario y artístico de Madrid (1835-1888). Támesis, 1971.

Saborit, Antonio, et al. La literatura en los siglos XIX y XX. Conaculta, 2013.

Staples, Anne. Recuento de una batalla inconclusa. La educación mexicana de Iturbide a Juárez. El Colegio de México, 2005.

Suárez de la Torre, Laura. "La construcción de una identidad nacional. (1821-1855)". La construcción del discurso nacional en México un anhelo persistente (siglos XIX y XX), coordinado por Nicole Giron, Instituto Mora, 2007.

Tornel, José María. Discurso pronunciado en la Alameda de la ciudad de México en el día 27 de septiembre de 1850.

Urías, Beatriz. "Educación para la democracia". Estudios, no. 12, 1988, pp. 29-51.

Vázquez Mantecón, María del Carmen. La palabra del poder. Vida pública de José María Tornel (1795-1853). Universidad Nacional Autónoma de México / Instituto de Investigaciones Históricas, 2008. Vázquez, Josefina Zoraida. Nacionalismo y educación en México. El Colegio de México, 1970.

Vélez, Pedro. Sección "Ministerio de Justicia e Instrucción Pública". El Siglo Diezy Nueve, 3 nov. 1842.

Zermeño, Guillermo. "El concepto intelectual en Hispanoamérica: génesis y evolución”. Historia Contemporánea, no. 27, 2003, pp. 777-778. 